\title{
COMPETÊNCIA PERCEBIDA NO ENSINO SECUNDÁRIO: DO CONCEITO À AVALIAÇÃO ATRAVÉS DE UM QUESTIONÁRIO COMPÓSITO
}

\author{
Joana Stocker ${ }^{2}$ \\ Luísa Faria ${ }^{1}$
}

Resumo: A competência percebida no domínio da realização académica corresponde aos juízos que os alunos constroem acerca das suas capacidades e competências pessoais, influenciando a respectiva motivação e desempenho. Este construto será analisado no quadro de um modelo conceptual compreensivo que integra diferentes dimensões motivacionais: concepções pessoais de inteligência, dimensões causais, auto-conceito e auto-eficácia académicos e competência emocional, propondo-se uma medida de avaliação compósita com 162 itens, o Questionário Compósito de Competência Percebida (QCCP). Serão apresentadas as fases de construção e adaptação - estudo-piloto com 385 alunos e estudo de validação com 1794 alunos, todos do secundário -, bem como os resultados de análises psicométricas com o QCCP. Este extraiu 44\% da variância total, revelou alphas entre 0,73 e 0,94 , correlações positivas entre a maior parte das dimensões, e um ajustamento local e global aceitável, após reespecificação do modelo estrutural mais representativo dos dados empíricos.

Palavras-chave: competência percebida; motivação escolar; realização escolar; ensino secundário; modelação de equações estruturais.

Perceived competence in secondary school: From concept to evaluation through a composite questionnaire (Abstract): Perceived competence in the academic achievement domain is described as students' judgments on their personal capacities and competences that influence their own motivation and achievement. This

\footnotetext{
${ }^{1}$ Faculdade de Psicologia e de Ciências da Educação da Universidade do Porto (FPCEUP).

2 Esta investigação foi financiada pela Fundação para a Ciência e a Tecnologia no âmbito de uma bolsa de doutoramento concedida a Joana Stocker (SFRH/BD/60225/2009).

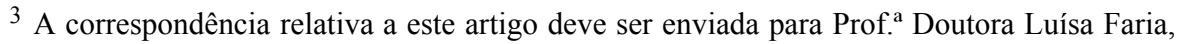
Faculdade de Psicologia e de Ciências da Educação da Universidade do Porto, Rua Alfredo Allen, 4200-135, Porto. Telefone: 226079 700. Fax: 226079 725. E-mail: lfaria@fpce.up.pt.
} 
construct will be analysed in the scope of a comprehensive conceptual model that integrates different motivational dimensions: personal conceptions of intelligence, causal dimensions, academic self-concept and self-efficacy and emotional competence, together with a new composite evaluation measure with 162 items, the Perceived Competence Composite Questionnaire (PCCQ). The construction and adjustment phases - pilot study with 385 students and validation study with 1794 students, all from secondary -, and the results of psychometric analyses with PCCQ will be presented. PCCQ extracted 44\% of total variance, revealed alphas between .73 and .94 , positive correlations between the majority of its dimensions, and an acceptable local and global adjustment, after re-specification of the structural model that better represents empirical data.

Keywords: perceived competence; academic motivation; academic achievement; secondary education; structural equation modeling.

\section{Introdução}

A competência percebida no domínio académico é uma dimensão auto-avaliativa que diz respeito às percepções e juízos que os alunos constroem acerca das suas capacidades e competências pessoais nos domínios da realização escolar (Faria, 2008). Desenvolvendo-se através das avaliações pessoais de experiências anteriores, a competência percebida funda-se na interpretação dos sucessos e dos fracassos, nas percepções de controlo das realizações, no feedback dos agentes de socialização e na reacção afectiva perante as consequências do desempenho individual (Harter, 1992). De acordo com Harter (1992), estes factores têm um impacto directo na competência percebida e na motivação do aluno. Paralelamente, o processo de auto-avaliação das percepções de competência pessoal pode provocar, ainda, uma reacção afectiva secundária que irá influenciar de igual modo a respectiva orientação motivacional. Assim, Harter (1992) evidencia uma relação directa entre a competência percebida e a motivação do aluno, mas também uma relação indirecta, através da mediação de reacções afectivas, reforçando a importância da competência percebida no domínio motivacional como, de resto, tinha já sido sugerido por Weiner (1985).

Deste modo, duas conclusões se sobrelevam do que foi referido: a importância da competência percebida para a motivação dos alunos e o seu carácter multidimensional. Efectivamente, decorrendo de interpretações, percepções e afectos, constituindo em si mesma um processo de formulação de juízos pessoais, e dando origem a novas reacções afectivas e a orientações motivacionais, a competência percebida apresenta-se como um construto compósito (Stocker, Pina Neves, \& Faria, 2010), integrando diferentes 
dimensões que se situam entre o continuum do pólo cognitivo e do pólo emocional. Assim, enquanto o pólo cognitivo diz respeito às interpretações das situações e resultados da realização, aos juízos pessoais e à auto-avaliação de competência, o pólo emocional diz respeito a todos os sentimentos e afectos decorrentes dos resultados da realização, do processo de auto-avaliação e das respectivas percepções de competência.

Ora, procurando analisar a competência percebida no seu sentido mais lato e compreensivo, neste estudo apresenta-se um modelo compósito da competência percebida, baseado num modelo formulado e investigado anteriormente, sobre as concepções pessoais de competência (Pina Neves \& Faria, 2005), mas apresentando agora variáveis cognitivas e variáveis emocionais: concepções pessoais de inteligência (CPI) - a minha competência intelectual pode ser desenvolvida?; dimensões causais - as causas dos meus resultados são internas, estáveis e controláveis por mim?; auto-conceito académico - sou bom/boa aluno(a)?; auto-eficácia académica - vou ter boas notas?; e competência emocional - consigo lidar com situações emocionalmente dificeis?.

\section{Concepções pessoais de inteligência}

As CPI, de acordo com a perspectiva de Dweck (1996, 1999), são definidas como teorias pessoais e implícitas que o aluno constrói acerca da natureza e desenvolvimento da sua inteligência, através de um processo auto-avaliativo (Ciochină \& Faria, 2006; Faria, 2008). Apesar de serem vistas num continuum, as CPI tendem a ser mais estáticas ou mais dinâmicas. Alunos com concepções estáticas da inteligência (fixed mindset) tendem a preocupar-se essencialmente com os seus resultados escolares objectivos e não com o processo de aprendizagem per se, uma vez que acreditam que a inteligência tem uma quantidade fixa e limitada, não sendo passível de desenvolvimento (Dweck, 2008; Faria, 2008). Assim, neste caso, o que importa é apenas a demonstração objectiva de inteligência, realizada sobretudo através da comparação social. Pelo contrário, alunos com CPI dinâmicas (growth mindset) vêem a inteligência como uma qualidade flexível (Ciochină \& Faria, 2006; Dweck, 2008; Faria, 2008) e acreditam no seu desenvolvimento através do empenho, esforço e investimento pessoal. Desta forma, torna-se evidente que a competência percebida de alunos com concepções estáticas será mais vulnerável, uma vez que vai depender obrigatória e directamente dos resultados obtidos. Ou seja, apesar do sucesso poder reforçar o sentimento de competência pessoal, o fracasso debilita-o, aumentando o risco de fuga ou evitamento de situações adversas, susceptíveis de desafiar e vulnerabilizar a competência pessoal (Dweck, 1999, 2008). 


\section{Atribuições e dimensões causais}

Do mesmo modo, as atribuições e dimensões causais têm sido reconhecidas como mediadoras importantes de padrões de comportamento mais ou menos adaptativos, nomeadamente nos domínios da motivação e do rendimento escolar, influenciando as realizações, a persistência e as expectativas de sucesso (Dweck, 1999; Perry, Stupnisky, Hall, Chipperfield, \& Weiner, 2010; Weiner, 1985). Weiner $(1985,2008)$ defende que perante os resultados das realizações escolares, existe o desejo de encontrar as causas do sucesso e, especialmente, do fracasso, como forma de compreensão, integração e transformação dessa experiência (Pina Neves \& Faria, 2008; Stocker, Pina Neves, \& Faria, 2010). O mesmo autor (Weiner, 1985) propõe uma taxonomia de três dimensões causais: locus de causalidade - se a causa do resultado é interna ou externa ao aluno; estabilidade - se a causa é estável ou instável ao longo do tempo; e controlabilidade - se a causa é controlável ou incontrolável pelo aluno. Globalmente, considera-se que um aluno que percepcione as causas de um sucesso como internas, estáveis e controláveis, e externas, instáveis e controláveis para o insucesso, protegerá e promoverá os seus níveis de competência percebida e de motivação (Weiner, 1985).

\section{Auto-conceito académico}

Por sua vez, o auto-conceito, de acordo com o modelo hierárquico e multidimensional de Shavelson, Hubner e Stanton (1976), tem origem num processo cognitivo de auto-avaliação realizado pelo indivíduo e diz respeito às crenças, percepções e características do mesmo, organizando e dando estrutura, coerência e significado às vivências pessoais (Hattie, 1992; Pajares \& Schunk, 2001). Marsh e Shavelson (1985), de acordo com a organização hierárquica do auto-conceito, apontam para a existência de auto-percepções globais e específicas do self, entre as quais o auto-conceito académico. O auto-conceito académico diz respeito às crenças do aluno acerca das suas competências e limites académicos, dos seus hábitos, gostos e interesses nos domínios escolares. Mais ainda, este construto pode integrar dimensões específicas da acção, ou seja, de acordo com o domínio disciplinar considerado (Marsh, Byrne, \& Shavelson, 1988; Pajares \& Schunk, 2001). Assim, no presente estudo, aborda-se o auto-conceito académico em três dimensões: auto-conceito assuntos escolares, auto-conceito verbal e auto-conceito Matemática. Tomando como referência as correlações positivas entre as auto-percepções dos alunos e a respectiva realização, considera-se que um auto-conceito académico positivo pode contribuir para uma melhor competência percebida, promovendo confiança no self académico e no desempenho individual (Marsh, Byrne, \& Shavelson, 1988; Pajares \& Schunk, 2001). 


\section{Auto-eficácia académica}

De acordo com Bandura (1977), a auto-eficácia é um construto microanalítico, devendo ser operacionalizado em função do domínio específico a avaliar. Neste caso, o domínio em questão é o académico, sendo possível, então, conceptualizar o construto da auto-eficácia académica (Stocker, Pina Neves, \& Faria, 2010). A auto-eficácia académica pode ser definida como o conjunto de expectativas que os alunos constroem acerca das capacidades pessoais para realizar tarefas, concretizar objectivos e alcançar resultados no domínio da realização escolar (Pina Neves \& Faria, 2007; Stocker, Pina Neves, \& Faria, 2010). À semelhança do auto-conceito académico, na auto-eficácia académica foram consideradas três dimensões: auto-eficácia escolar geral, auto-eficácia em Português e auto-eficácia em Matemática. Assim, quanto mais positivas forem as expectativas dos alunos face aos seus resultados, melhores deverão ser os níveis de competência percebida, uma vez que acreditam na qualidade do seu trabalho e antecipam resultados de sucesso (Pajares \& Schunk, 2001).

\section{Competência emocional}

Finalmente, a competência emocional é definida como a capacidade de o aluno perceber, reconhecer, expressar, regular e gerir emoções, para compreender sentimentos e cognições subsequentes (Mayer \& Salovey, 1997; Salovey, Mayer, \& Goldman, 1995; Stocker, Pina Neves, \& Faria, 2010). Neste sentido, três dimensões ganham relevo: percepção emocional identificar, perceber e interpretar emoções em si e nos outros -, expressão emocional - exteriorizar sentimentos de forma adequada -, e capacidade para regular a emoção - regular e gerir emoções: reforçar emoções positivas, como o orgulho e a esperança, e ultrapassar negativas, como a culpa e a vergonha (Faria et al., 2006; Faria, Pina Neves, Stocker, Fontes Costa, \& Costa, 2010; Lima Santos \& Faria, 2005; Salovey, Mayer, \& Goldman, 1995). Assim, diferentes autores relevam o papel da emoção na competência percebida e, consequentemente, na motivação, no desempenho e na realização académica (Frederickson, 2001; Pekrun, Maier, \& Elliot, 2009; Perry, Stupnisky, Hall, Chipperfield, \& Weiner, 2010; Weiner, 1985). Efectivamente, alunos com elevados níveis de percepção de competência emocional tendem a interpretar os resultados académicos de forma mais adaptativa, e a percepcionar mais ajustadamente as suas potencialidades e os seus limites, mostrando-se mais curiosos, optimistas e interessados (Mayer \& Salovey, 1997; Pekrun, Maier, \& Elliot, 2009).

Desta forma, estes cinco construtos psicológicos constituem e organizam-se conjunta e integradamente numa variável compósita que designamos 
por competência percebida que, por sua vez, se relaciona, quer directa quer indirectamente, com a motivação académica dos alunos.

\section{Objectivos}

São vários os estudos que investigam estas variáveis psicológicas individual e isoladamente, dificultando a compreensão das relações que estabelecem entre si e com os resultados escolares. Procurando contrariar esta tendência, no presente artigo pretende-se contribuir para uma compreensão alargada e integrada da competência percebida, nomeadamente no que se refere às possibilidades de avaliação da mesma numa perspectiva multidimensional. Deste modo, apresentam-se as etapas envolvidas na construção, adaptação e validação de um instrumento compósito, Questionário Compósito de Competência Percebida (QCCP), que integra dimensões e itens dos construtos que têm vindo a ser apresentados (CPI, atribuições e dimensões causais, auto-conceito e auto-eficácia académicos e competência emocional), seleccionados de escalas já existentes e adaptadas à população portuguesa. Pretende-se igualmente analisar as respectivas qualidades psicométricas, e, finalmente, contribuir para o incremento da avaliação, de modo compreensivo e multidimensional, das percepções de competência pessoal de alunos do ensino secundário.

\section{Método}

\section{Participantes}

Participaram neste estudo 1794 alunos do ensino secundário do Porto (37,5\% do $10^{\circ}$ ano, $32,3 \%$ do $11^{\circ}$ ano e $30,2 \%$ do $12^{\circ}$ ano), de escolas públicas $(60,1 \%)$ e privadas, com idades compreendidas entre os 14 e os 21 anos $(M=16,3 ; M d=16,0 ; M o=16 ; D P=1,06)$. A maior parte dos alunos é do sexo feminino (54,6\%), do nível sócio-económico (NSE) médio-alto (20,4\% do NSE médio-baixo, $24,2 \%$ do NSE médio, $27,8 \%$ do NSE médio-alto e $27,6 \%$ do NSE alto) e do curso científico-humanístico de Ciências e Tecno$\operatorname{logias}(44 \%)$.

\section{Instrumento}

A versão final do QCCP foi alcançada através de duas fases sequenciais distintas: 1) revisão da literatura e análise dos instrumentos existentes para avaliar cada construto; e 2) realização de um estudo-piloto com 385 alunos do ensino secundário. 
Na primeira fase, após a revisão da literatura no domínio da competência percebida, foram seleccionados os instrumentos que apresentaram melhores resultados em diversas investigações no contexto português e que, assim, integraram o QCCP: Escala de Concepções Pessoais de Inteligência (ECPI), construída e validada por Faria (2006); Questionário de Atribuições $e$ Dimensões Causais (QADC), de Pina Neves e Faria (2008); Self-Description Questionnaire III (SDQIII), adaptado por Faria e Fontaine (1992); Escala de Auto-Eficácia Académica (EAEA), de Pina Neves e Faria (2006); e Emotional Skills and Competence Questionnaire, validado para o contexto português por Lima Santos e Faria (Questionário de Competência Emocional - QCE -, Faria \& Lima Santos, 2011; Lima Santos \& Faria, 2005). Assim, foram mantidas todas as dimensões teóricas destes instrumentos, com excepção do SDQIII, em que apenas se utilizou a dimensão académica do auto-conceito, e procedeu-se à análise dos itens de cada instrumento, comparando os resultados das suas qualidades psicométricas em diferentes investigações, em momentos e com populações diferentes, de modo a seleccionar os itens com melhores indicadores psicométricos.

No final, o QCCP integrou um total de 162 itens: 20 itens da ECPI 10 itens na CPI estática e 10 na CPI dinâmica; 48 itens do QADC - 16 itens no locus de causalidade, 16 na estabilidade e 16 na controlabilidade; 30 itens do SDQIII - 10 itens no auto-conceito verbal, 10 no auto-conceito Matemática e 10 no auto-conceito assuntos escolares; 22 itens da EAEA - sete itens na auto-eficácia em Português, oito na auto-eficácia em Matemática e sete na auto-eficácia escolar geral; e, por fim, 42 itens do QCE - 14 itens na percepção emocional, 14 na expressão emocional e 14 na capacidade para lidar com a emoção. Todos os itens estão organizados por construto, com instruções intercalares e com escalas de resposta de tipo Likert (Quadro 1), de acordo com a ordem seguinte: QCE, ECPI, EAEA, SDQIII e QADC.

Numa segunda fase, com o objectivo de testar a compreensão uniforme e unívoca das instruções e dos itens por parte dos alunos e, posteriormente, de efectuar um refinamento do instrumento, foi realizado um estudo-piloto. A amostra deste estudo foi constituída por 385 estudantes, equitativamente distribuídos pelos três anos do ensino secundário do Grande Porto $\left(10^{\circ}\right.$ ano $-36,6 \% ; 11^{\circ}$ ano $-31,9 \% ; 12^{\circ}$ ano $\left.-31,4 \%\right), 55,6 \%$ raparigas e $44,4 \%$ rapazes, com idades compreendidas entre os 13 e os 22 anos $(M=16,3 ; M d=16,0 ; M o=16 ; \mathrm{DP}=1,25)$ e de nível sócio-profissional alto $(31,9 \%)$, médio $(34,2 \%)$ e baixo $(33,9 \%)$, que responderam colectivamente ao QCCP, não se tendo observado dificuldades assinaláveis.

No que respeita as qualidades psicométricas do QCCP, globalmente, os resultados mostraram-se satisfatórios. Assim, relativamente à consistência interna, analisada através do alpha de Cronbach, foram encontrados bons valores, situados entre 0,72 e 0,95 , sendo as dimensões da EAEA os seus melhores representantes (entre 0,89 e 0,95 ). 
Quadro 1 - Caracterização dos questionários que integram o QCCP

\begin{tabular}{|c|c|c|c|c|}
\hline Quest & Dim & Exemplos de itens & & $\begin{array}{l}\text { nplitude da escala de } \\
\text { Likert }\end{array}$ \\
\hline \multirow{3}{*}{ QCE } & $\mathrm{PE}$ & $\begin{array}{c}\text { Percebo quando alguém está em } \\
\text { baixo. }\end{array}$ & \multirow{3}{*}{$1-6$} & \multirow{3}{*}{ Nunca - Sempre } \\
\hline & $\mathrm{EE}$ & $\begin{array}{c}\text { Consigo exprimir a forma como me } \\
\text { sinto. }\end{array}$ & & \\
\hline & CLE & Tento manter o bom humor. & & \\
\hline \multirow{2}{*}{ ECPI } & CPI D & $\begin{array}{c}\text { Quando aprendo coisas novas a } \\
\text { minha inteligência aumenta. }\end{array}$ & \multirow{8}{*}{$1-6$} & \multirow{8}{*}{$\begin{array}{l}\text { Concordo totalmente - } \\
\text { Discordo totalmente }\end{array}$} \\
\hline & CPI E & $\begin{array}{l}\text { Não posso mudar muito a inteligên- } \\
\text { cia que possuo. }\end{array}$ & & \\
\hline \multirow{3}{*}{ EAEA } & AE P & $\begin{array}{c}\text { Este ano a minha nota a Português } \\
\text { vai ser uma das minhas melhores } \\
\text { notas. }\end{array}$ & & \\
\hline & $\mathrm{AE} \mathrm{M}$ & $\begin{array}{c}\text { Vou ter uma boa nota a Matemática } \\
\text { no final do ano. }\end{array}$ & & \\
\hline & AE EG & $\begin{array}{c}\text { Este ano vou ser bem sucedido(a) } \\
\text { na escola. }\end{array}$ & & \\
\hline \multirow{3}{*}{ SDQIII } & $\mathrm{AC} \mathrm{V}$ & $\begin{array}{c}\text { Tenho uma boa capacidade de leitu- } \\
\text { ra. }\end{array}$ & & \\
\hline & $\mathrm{AC} \mathrm{M}$ & A Matemática faz-me sentir incapaz. & & \\
\hline & $\mathrm{AC} \mathrm{AE}$ & $\begin{array}{l}\text { Sou bom(boa) na maior parte das } \\
\text { disciplinas. }\end{array}$ & & \\
\hline \multirow{3}{*}{ QADC } & Locus & A capacidade para aprender... & \multirow{3}{*}{$1-5$} & $\begin{array}{c}\text {...só diz respeito a } \\
\text { mim }-\ldots \text { só diz respei- } \\
\text { to aos outros/meio. } \\
\end{array}$ \\
\hline & Est & A participação nas aulas... & & $\begin{array}{c}\text {..nunca varia ao longo } \\
\text { do ano escolar - } \\
\text {...varia sempre ao } \\
\text { longo do ano escolar. }\end{array}$ \\
\hline & Cont & A ansiedade nos testes... & & $\begin{array}{l}\text {... só depende de mim } \\
\text { - ...não depende nada } \\
\text { de mim. }\end{array}$ \\
\hline
\end{tabular}

Legenda: Quest - questionário; Dim - dimensões; QCE - Questionário de Competência Emocional; ECPI - Escala de Concepções Pessoais de Inteligência; EAEA - Escala de Auto-Eficácia Académica; SDQIII - Self-Description Questionnaire III; QADC Questionário de Atribuições e Dimensões Causais; PE - percepção emocional; EE expressão emocional; CLE - capacidade para lidar com a emoção; CPI D - concepções pessoais de inteligência dinâmicas; CPI E - concepções pessoais de inteligência estáticas; AE P - auto-eficácia em Português; AE M - auto-eficácia em Matemática; AE EG - auto-eficácia escolar geral; AC V - auto-conceito verbal; AC M - auto-conceito Matemática; AC AE - auto-conceito assuntos escolares; Est - estabilidade; Cont - controlabilidade. 
Para testar a validade factorial do instrumento, procedeu-se à realização de uma análise factorial exploratória em componentes principais, com rotação varimax, extraindo-se 14 factores, um por cada dimensão analisada, que extraem $50 \%$ da variância total dos resultados. Os índices globais de saturação e de comunalidade dos itens tendem a situar-se, globalmente, acima de 0,30 .

No que se refere à sensibilidade do instrumento, as respectivas dimensões apresentam médias e medianas aproximadas, valores máximos e mínimos claramente afastados, bem como coeficientes de assimetria e de curtose próximos da unidade (à excepção da CPI dinâmica, do locus, da expressão emocional e da capacidade para lidar com a emoção, que revelam valores de curtose mais elevados, entre 1,84 e 2,49).

A partir dos indicadores recolhidos realizou-se um primeiro refinamento do QCCP, que consistiu na reformulação dos itens com piores indicadores psicométricos e que suscitaram dúvidas ligeiras no estudo-piloto. Globalmente, o sentido/significado dos itens foi mantido, procurando-se apenas promover a sua clarificação.

\section{Procedimento}

Para este estudo foram seleccionadas escolas públicas e privadas com ensino secundário de diferentes zonas geográficas da cidade do Porto (Zona Oriental e Ocidental), incluindo quatro freguesias distintas, com o objectivo de obter uma amostra representativa de diferentes realidades sociais, culturais e económicas do Porto. Dentro de cada escola, a selecção das respectivas turmas foi totalmente aleatória.

Após a autorização das instituições escolares, oficializada num documento escrito, foi pedida a autorização dos Encarregados de Educação dos alunos das turmas seleccionadas, numa carta que explicava a temática e objectivos do estudo, e as condições de administração dos questionários, nomeadamente o carácter confidencial e voluntário. Em caso de autorização, a carta era assinada e devolvida à escola.

A administração do QCCP foi realizada colectivamente, por turma, em tempos lectivos e na sala de aula. Os procedimentos foram uniformizados para todas as turmas e o tempo de preenchimento do questionário variou entre 20 e 40 minutos.

\section{Análise de dados}

No que respeita o tratamento dos dados, foi utilizado o SPSS (versão 17.0) para as seguintes análises: análise factorial exploratória (AFE), consistência interna das dimensões (alpha de Cronbach), validade interna dos itens (correlação item x total corrigido), correlação entre dimensões, sensibilidade 
e poder discriminativo; e o $E Q S$ (versão 6.1) para as análises factoriais confirmatórias (AFC).

A sensibilidade do QCCP foi analisada através das medidas de tendência central (média, moda e mediana), de dispersão (desvio-padrão e amplitude) e de distribuição (assimetria e curtose) para as várias dimensões.

Para o estudo do poder discriminativo do instrumento compósito, foi analisada a percentagem de escolha das alternativas de resposta de cada dimensão, sendo posteriormente realizado um somatório das alternativas de concordância e das alternativas de discordância, de modo a aceder à tendência global das respostas.

$\mathrm{Na}$ AFC, as análises foram realizadas com matrizes de covariância construídas pelo EQS, através do método de estimação máxima verosimilhança (maximum likelihood - ML). Uma vez que a nossa amostra, de acordo com os indicadores do EQS, violava os princípios da normalidade (valor de Mardia superior a 5) pediu-se a opção robusta em todas as análises (ML, robust - correcção de Satorra-Bentler - Satorra \& Bentler, 1994). Para cada modelo foram tidos em conta:

- matriz de covariância residual estandardizada - discrepância entre as covariâncias da matriz do modelo proposto e as da matriz obtida, existindo um resíduo para cada par de variáveis que não deve ultrapassar o valor 2,58. A distribuição dos resíduos deve ser simétrica e centrada em zero (Byrne, 2006).

- índices de ajustamento global - analisam o modelo como um todo. São eles:

a) Qui-Quadrado de Independência (Independence Chi-Square Statistic) - avalia a melhoria dos modelos alternativos face ao modelo nulo. Assim, o qui-quadrado de independência para o modelo nulo deve ser substancialmente mais alto que o qui-quadrado para o modelo alternativo, pois indica que o modelo nulo não é ajustado;

b) Qui-Quadrado (Chi-Square Statistic - $\chi^{2}$ ) - discrepância entre o modelo proposto e o modelo obtido, devendo ser o mais baixo possível e não-significativo;

c) Non-Normed Fit Index (NNFI) e Comparative Fit Index (CFI) índices de comparação entre o modelo proposto e o modelo nulo. Variando entre zero e um, o valor original de referência para um bom ajustamento do modelo era 0,90 , tendo sido revisto para 0,95 (Hu \& Bentler, 1999);

d) Root Mean-Squared Residuals Standardized (RMR Rt $_{\text {st }}$ e Root Mean-Squared Error of Approximation (RMSEA) - índices absolutos que verificam em que medida o modelo proposto se ajusta à amostra. Quanto mais ajustado o modelo, menor o valor destes indicado- 
res. O RMR $R_{\text {st }}$ representa o valor médio dos resíduos estandardizados, não devendo ultrapassar 0,08. O RMSEA considera o erro de aproximação do modelo à população e não deve ultrapassar 0,06 (Hu \& Bentler, 1999).

- índices de ajustamento local - indicadores que analisam os parâmetros individuais do modelo como: significância dos parâmetros estimados e respectivos valores de saturação, variância-erro, entre outros.

- coeficiente de $R^{2}$ (Squared Multiple Correlation Coefficient) - avalia a fiabilidade individual das variáveis manifestas, estimando a respectiva quantidade de variância capturada pelo factor latente, não devendo ser inferior a 0,25 (Maroco, 2010).

No Modelo 1 do QCCP, não se obtendo bons valores de partida (start values), recorreu-se ao procedimento retest, que estima automaticamente estes valores e as respectivas saturações (Byrne, 2006). Este procedimento é usualmente utilizado em modelos complexos, facilitando o processo iterativo no estabelecimento dos parâmetros estimados, evitando problemas de não-convergência.

Por fim, todos os modelos foram reespecificados, isto é, modificados através, por exemplo, da eliminação de vias não significativas, da libertação ou fixação de parâmetros, da correlação de erros de medida e/ou da associação de um item a outro factor além do proposto (loadings cruzados), de forma a diminuir significativamente o $\chi^{2}$ e a promover o ajustamento do modelo (Byrne, 2006; Maroco, 2010). Algumas destas decisões foram também apoiadas nas sugestões dadas pelo Lagrange Multiplier Test (LM Test), um teste multivariado que estima os índices de modificação para procedimentos alternativos.

\section{Resultados}

\section{Análise factorial exploratória}

Quanto à validade factorial do QCCP, realizada através de análises factoriais exploratórias (AFE) em componentes principais com rotação varimax, foi pedida a extracção de 14 factores, como no estudo-piloto, correspondentes a cada uma das dimensões teóricas do QCCP. Contudo, uma vez que todos os itens saturaram os primeiros doze factores, optou-se por aceitar um modelo com doze factores, que explica $44 \%$ da variância total dos resultados. No teste de Kaiser-Meyer-Olkin (KMO) foi obtido o valor de 0,92, o que revela uma boa adequação da amostra ao modelo factorial. Por sua vez, o teste de esfericidade de Bartlett apresentou valores adequados 
$\left(\chi^{2}=88217,79 ; p=0,00\right)$, sugerindo que a matriz de intercorrelações difere de uma matriz de identidade, estando as variáveis correlacionadas entre si.

Globalmente, cada uma das dimensões do QADC e do QCE saturaram factores independentes, diferenciando-se dos restantes; a EAEA e o SDQIII tendem a agrupar-se em torno das dimensões Português vs. Matemática; e, por fim, a ECPI saturou um único factor, com a excepção de cinco itens da CPI estática, relacionados com a demonstração de inteligência. Assim vejamos: o Factor 1 corresponde aos itens de Matemática da EAEA e do SDQIII e aos itens académicos gerais da EAEA, extraindo $9 \%$ da variância total dos resultados; o Factor 2 é saturado essencialmente por itens da dimensão verbal da EAEA e do SDQIII, correspondendo a 6\% da variância; o Factor 3 integra todos os itens da CPI dinâmica e cinco itens da CPI estática (ECPI) e extrai $5 \%$ da variância total; o Factor 4 é saturado por todos os itens de percepção emocional e o Factor 5 pelos itens de expressão emocional (QCE), extraindo cada um 4\% da variância dos resultados; por sua vez, o Factor 6 e o Factor 7 representam todos os itens da estabilidade e do locus (QADC com excepção de quatro itens do locus), respectivamente, correspondendo a $4 \%$ e a $2 \%$ da variância; dos restantes factores, cada um extrai $2 \%$ da variância total dos resultados, sendo que o Factor 8 reúne essencialmente itens da dimensão auto-conceito assuntos escolares (SDQIII), o Factor 9 agrupa 11 itens da controlabilidade (QADC), o Factor 10 é constituído por 10 itens da capacidade para lidar com a emoção (QCE), o Factor 11 mistura itens semelhantes da controlabilidade e do locus (QADC) e, por fim, o Factor 12 integra proeminentemente itens da CPI estática (ECPI). Finalmente, os índices de saturação e de comunalidade dos itens são globalmente iguais ou superiores a 0,30 .

\section{Consistência interna das dimensões e validade interna dos itens}

A análise do alpha de Cronbach revela bons valores de consistência interna para as dimensões do QCCP, tendo como referência o valor crítico de 0,70 , já que se situam entre 0,73 e 0,94 , sendo as dimensões no domínio da Matemática da EAEA e do SDQIII as mais consistentes (Quadro 2). As dimensões com piores resultados, correspondem à capacidade para lidar com a emoção ( $\mathrm{QCE}-\alpha=0,73$ ), à controlabilidade (QADC $-\alpha=0,73$ ), ao locus $(\mathrm{QADC}-\alpha=0,77)$ e à CPI estática (ECPI $-\alpha=0,77)$.

Os índices de correlação item x total corrigido (ritc), que correspondem à correlação de cada item com o somatório da respectiva dimensão excluindo o próprio item, corroboram os resultados da consistência interna, já que todos os itens apresentam um valor de correlação superior a 0,20 , com excepção do item 36 da capacidade para lidar com a emoção (QCE), do item 2 da CPI estática (ECPI), do item 6 do locus (QADC) e do item 13 da controlabilidade (QADC), sendo que estas foram as dimensões com menor con- 
sistência interna e em que estes itens (com excepção do item do locus) contribuem para a diminuição do alpha das mesmas.

Quadro 2 - Valores de alpha e das correlações dos itens com o total da respectiva dimensão

\begin{tabular}{|c|c|c|c|c|}
\hline Dimensões & $\begin{array}{l}\mathrm{N}^{\mathrm{o}} \\
\text { itens }\end{array}$ & alpha & $\begin{array}{c}\text { Variação do valor de } \\
\text { alpha, excluindo os itens } \\
\text { um a um }\end{array}$ & $\begin{array}{l}\text { Correlação item x } \\
\text { total corrigido (ritc) }\end{array}$ \\
\hline $\begin{array}{l}\text { Percepção emo- } \\
\text { cional }\end{array}$ & 14 & 0,87 & Alpha diminui sempre & 0,42 a 0,64 \\
\hline $\begin{array}{l}\text { Expressão emo- } \\
\text { cional }\end{array}$ & 14 & 0,87 & Alpha diminui sempre & 0,35 a 0,73 \\
\hline $\begin{array}{l}\text { Capacidade lidar } \\
\text { emoção }\end{array}$ & 14 & 0,73 & $\begin{array}{l}\text { Alpha aumenta para } 0,75 \\
\text { excluindo o item n. }{ }^{\text {o }} 36\end{array}$ & 0,12 a 0,50 \\
\hline CPI dinâmica & 10 & 0,90 & $\begin{array}{l}\text { Alpha diminui sempre } \\
\text { Alpha aumenta para } 0,81 \\
\text { excluindo o item } \text { n. }^{\circ} 2\end{array}$ & 0,54 a 0,75 \\
\hline CPI estática & 10 & 0,77 & $\begin{array}{c}\text { Alpha aumenta para } 0,78 \\
\text { excluindo os itens } \text { n. }^{\circ} 4 \mathrm{e} \\
18\end{array}$ & 0,08 a 0,71 \\
\hline AE Português & 7 & 0,87 & Alpha diminui sempre & 0,57 a 0,81 \\
\hline AE Matemática & 8 & 0,94 & Alpha diminui sempre & 0,62 a 0,90 \\
\hline AE escolar geral & 7 & 0,91 & Alpha diminui sempre & 0,55 a 0,83 \\
\hline AC verbal & 10 & 0,84 & $\begin{array}{l}\text { Alpha aumenta para } 0,85 \\
\text { excluindo o item n } .^{\circ} 11\end{array}$ & 0,35 a 0,68 \\
\hline AC Matemática & 10 & 0,93 & Alpha diminui sempre & 0,65 a 0,84 \\
\hline $\begin{array}{l}\text { AC assuntos } \\
\text { escolares }\end{array}$ & 10 & 0,86 & Alpha diminui sempre & 0,40 a 0,68 \\
\hline Locus & 16 & 0,77 & Alpha diminui sempre & 0,15 a 0,48 \\
\hline Estabilidade & 16 & 0,87 & $\begin{array}{c}\text { Alpha aumenta para } 0,88 \\
\text { excluindo o item n. }{ }^{\circ} 9\end{array}$ & 0,35 a 0,65 \\
\hline Controlabilidade & 16 & 0,73 & $\begin{array}{c}\text { Alpha aumenta para } 0,74 \\
\text { excluindo o item } \mathrm{n}^{\circ} 13\end{array}$ & Entre 0,14 e 0,44 \\
\hline
\end{tabular}

Legenda: $\mathrm{CPI}$ - concepções pessoais de inteligência; $\mathrm{AE}$ - auto-eficácia; $\mathrm{AC}$ - auto-conceito.

\section{Correlação entre as dimensões}

A validade externa, que diz respeito à relação entre as dimensões de determinado construto ou às relações entre dimensões de construtos diferentes, foi estudada através da correlação entre as várias dimensões da competência percebida (Quadro 3). Assim, espera-se que os coeficientes de correlação sejam mais fortes no caso da associação entre dimensões de um mes- 
mo construto, sugerindo validade convergente na sua avaliação, e mais fracos no caso da associação entre dimensões de diferentes construtos, revelando validade divergente. Contudo, é esperada uma associação significativa entre todas as dimensões, já que o modelo teórico subjacente a este instrumento considera as várias dimensões como constituindo o construto de competência percebida.

Tal como previsto, as dimensões analisadas apresentam globalmente correlações mais fortes intra-construto do que inter-construto, evidenciando níveis de convergência, por um lado, e de divergência, por outro.

Quadro 3 - Correlações entre as dimensões do QCCP

\begin{tabular}{|c|c|c|c|c|c|c|c|c|c|c|c|c|c|}
\hline & 2. & 3. & 4. & 5. & 6. & 7. & 8. & 9. & 10. & 11. & 12. & 13. & 14. \\
\hline 1. $\mathrm{PE}$ & 52 & & & & & & & & & & 0,00 & 0.00 & \\
\hline . $\mathrm{E}$ & & & & & & & & & & & & & \\
\hline CLE & ---- & & & & & & & & & & & 02 & \\
\hline ( & $\ldots$ & ---- & & & & & & & & & & & \\
\hline ( & & & & ---- & & & & & & & & & \\
\hline 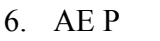 & ---- & -- & & & ---- & & & & & & 0,02 & & \\
\hline 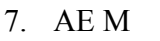 & & -- & -- & & ---- & ---- & & & & & & & \\
\hline 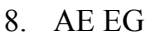 & & & & & & & & & & & & & \\
\hline & & & & & & & & ---- & & & & & \\
\hline & -- & ---- & ---- & -- & ---- & ---- & ---- & ---- & ---- & $0,29 * *$ & $0,08^{* *}$ & & \\
\hline$\Gamma$ & ---- & ---- & & -- & -- & -- & ---- & ---- & ---- & ---- & 0,02 & $0,20 * *$ & $* 0,09$ \\
\hline 1 & ---- & ---- & --- & ---- & ---- & ---- & ---- & ---- & --- & ---- & ---- & 0,04 & $0,47^{*}$ \\
\hline & & & & ---- & -- & -- & ---- & ---- & -- & ---- & ---- & ---- & $0,09 *$ \\
\hline 4. Cont & ---- & ---- & ---- & ---- & ---- & ---- & ---- & ---- & ---- & ---- & ---- & ---- & ---- \\
\hline
\end{tabular}

Legenda: PE - percepção emocional; EE - expressão emocional; CLE - capacidade para lidar com a emoção; CPI D - concepções pessoais de inteligência dinâmicas; CPI E - concepções pessoais de inteligência estáticas; AE P - auto-eficácia em Português; AE M - auto-eficácia em Matemática; AE EG - auto-eficácia escolar geral; AC V - auto-conceito verbal; AC M - auto-conceito Matemática; AC AE - auto-conceito assuntos escolares; Est - estabilidade; Cont - controlabilidade.

${ }^{*} p<0,05 . * * p<0,01$.

\section{Relações intra-construto}

Globalmente, as relações intra-construto tendem a ser significativas e positivas, embora algumas delas sejam fracas. Assim, observam-se correlações positivas e mais fortes $(>0,30)$ entre as dimensões do QCE, da ECPI, e entre percepções de causalidade mais internas e controláveis (QADC). A excepção surge para a auto-eficácia (EAEA) e para o auto-conceito (SDQIII), em que as correlações mais fortes parecem organizadas por domínio escolar (Português e Matemática) e não por construto (auto-eficácia vs. auto-conceito). Efectivamente, este resultado corrobora o modelo factorial 
encontrado, já que as dimensões da auto-eficácia e do auto-conceito académicos misturam-se de acordo com a sua afinidade no domínio escolar. Este fenómeno foi já observado em investigações anteriores (Pajares \& Schunk, 2001; Pietsch, Walker, \& Chapman, 2003), e encontra possível explicação no facto de as escalas de auto-eficácia e de auto-conceito partilharem alguma semelhança conceptual, que se acentua quando se inter-correlacionam as dimensões nos mesmos domínios académicos. Dentro do construto da auto-eficácia, as dimensões mantêm relações mais fortes entre si $(\geq 0,30)$, comparativamente com as dimensões do auto-conceito, já que o auto-conceito Matemática apresenta uma relação fraca com o auto-conceito verbal $(0,05)$.

\section{Relações inter-construtos}

No que diz respeito às relações inter-construtos, a magnitude das correlações varia de acordo com as dimensões em análise, pelo que apresentaremos apenas os resultados mais relevantes. Saliente-se que as correlações fracas ou não significativas correspondem, essencialmente, ao QADC. Assim, as percepções de competência emocional associam-se positiva e moderadamente (entre 0,20 e 0,33 ) com as CPI dinâmicas, com as percepções de eficácia e de competência académicas gerais e de Português (no domínio da Matemática, as correlações são fracas ou não significativas).

Em relação às CPI, concepções menos estáticas da inteligência estão relacionadas de forma moderada com o auto-conceito verbal $(0,22)$ e assuntos escolares $(0,27)$.

Tal como já foi referido, para as dimensões da auto-eficácia e do auto-conceito académicos os coeficientes de correlação são superiores para as dimensões afins dos dois construtos. Assim, as associações mais fortes surgem entre a auto-eficácia em Matemática e o auto-conceito Matemática $(0,76)$, entre a auto-eficácia escolar geral e o auto-conceito assuntos escolares $(0,67)$ e entre a auto-eficácia em Português e o auto-conceito verbal $(0,61)$. Todas estas relações são positivas e significativas, pelo que podemos concluir que quanto mais elevadas são as expectativas académicas nas três dimensões consideradas, mais positivo é o auto-conceito e vice-versa, reforçando os resultados de investigações anteriores (Pietsch, Walker, \& Chapman, 2003).

Por sua vez, a estabilidade é a dimensão causal que mantém relações moderadas (entre 0,20 e 0,21) com algumas dimensões psicológicas: auto-eficácia e auto-conceito Matemática, e auto-conceito assuntos escolares, sendo que quanto mais positivas estas forem, mais estáveis serão as atribuições causais no contexto académico. 
Sensibilidade das dimensões e poder discriminativo dos itens

No que se refere à análise da sensibilidade do instrumento, o recurso às estatísticas descritivas permitiu concluir que, no cômputo geral, o mesmo apresenta médias e medianas aproximadas, valores máximos e mínimos claramente afastados, bem como coeficientes de assimetria e de curtose próximos da unidade (à excepção das dimensões do QCE, da CPI dinâmica e do locus, como se verifica no Quadro 4). Assim, podemos concluir que estes indicadores enquadram globalmente as respostas dos sujeitos dentro dos parâmetros da "curva normal".

Quadro 4 - Medidas de tendência central, de dispersão e de distribuição para as dimensões do QCCP

\begin{tabular}{lccccccccc}
\hline \multicolumn{1}{c}{ Dimensões } & $\begin{array}{c}\mathrm{N}^{\mathrm{o}} \\
\text { Itens }\end{array}$ & $M$ & $M d$ & Mo & $D P$ & Mín. & Máx. & Assimetria & Curtose \\
\hline $\begin{array}{l}\text { Percepção emo- } \\
\text { cional }\end{array}$ & 14 & 63,2 & 64,0 & 65 & 7,9 & 5 & 84 & $-0,66$ & 2,38 \\
$\begin{array}{l}\text { Expressão emo- } \\
\text { cional }\end{array}$ & 14 & 64,7 & 65,5 & 65 & 9,1 & 6 & 84 & $-0,85$ & 1,91 \\
Capacidade & & & & & & & & & \\
lidar emoção & 14 & 65,6 & 66,0 & 65 & 7,3 & 21 & 83 & $-0,76$ & 1,86 \\
CPI dinâmica & 10 & 45,6 & 47,0 & 49 & 8,7 & 10 & 60 & $-1,17$ & 2,01 \\
CPI estática & 10 & 43,2 & 44,0 & 47 & 8,2 & 15 & 60 & $-0,42$ & $-0,22$ \\
AE Português & 7 & 31,4 & 32,0 & 35 & 6,3 & 2 & 42 & $-0,64$ & 0,50 \\
AE Matemática & 8 & 35,3 & 37,0 & 40 & 9,2 & 1 & 48 & $-0,92$ & 0,81 \\
AE escolar geral & 7 & 33,0 & 34,0 & 36 & 6,2 & 7 & 42 & $-0,88$ & 0,98 \\
AC assuntos & 10 & 44,5 & 45,0 & 44 & 8,0 & 10 & 60 & $-0,56$ & 0,56 \\
escolares & 10 & 43,9 & 44,0 & 45 & 7,9 & 10 & 60 & $-0,30$ & $-0,10$ \\
AC verbal & 10 & 35,7 & 37,0 & 33 & 14,0 & 1 & 60 & $-0,32$ & $-0,66$ \\
AC Matemática & 16 & 65,5 & 66,0 & 65 & 6,7 & 10 & 80 & $-0,88$ & 2,92 \\
Locus & 16 & 52,5 & 53,0 & 52 & 10,2 & 15 & 80 & $-0,50$ & 0,30 \\
Estabilidade & 16 & 66,7 & 62,0 & 62 & 6,7 & 38 & 80 & 0,02 & $-0,13$ \\
Controlabilidade & 16 &
\end{tabular}

Legenda: CPI - concepções pessoais de inteligência; AE - auto-eficácia; AC - auto-conceito.

No que concerne o poder discriminativo, os resultados foram menos satisfatórios na maioria das escalas, pois apesar de se observar algum equilíbrio na escolha das várias alternativas de resposta, é igualmente verificado um ligeiro pendor para as respostas de concordância (entre $27 \%$ e $97 \%$ ), revelando concordância com os itens positivos e discordância com os itens negativos, o que poderá ser indicador da provável influência da desejabilida- 
de social. Mais especificamente, os itens do SDQIII e da EAEA revelam um poder discriminativo mais forte do que as restantes, evidenciando uma distribuição de respostas mais equilibrada pelas diferentes alternativas.

\section{Análise factorial confirmatória}

A análise factorial confirmatória (AFC) constitui um procedimento fundamental em qualquer estudo que ambicione testar a validade de construto de um instrumento, sendo por isso um procedimento essencial no quadro dos objectivos deste estudo.

Tal como para a AFE, procurou-se realizar uma AFC que integrasse todos os itens do QCCP, correspondendo a 14 factores. Contudo, esta análise revelou-se inexequível face à complexidade e extensão do modelo proposto. Optou-se então pela realização preliminar de AFC's para cada escala (ECPI, QADC, SDQIII, EAEA e QCE), de modo a aferir a sua organização e a seleccionar os itens com melhores indicadores psicométricos (Quadro 5). Estes itens, considerados os mais representativos do QCCP e que melhor avaliam a competência percebida, integrariam posteriormente uma AFC mais parcimoniosa do instrumento compósito.

No que diz respeito à ECPI, os índices de ajustamento para o primeiro modelo foram claramente maus ( $\mathrm{NNFI}=0,84, \mathrm{CFI}=0,86, \mathrm{RMSEA}=0,07$ ), com a excepção do $\mathrm{RMR}_{\mathrm{st}}(0,07)$. Para encontrar um modelo final aceitável, foram excluídos os itens com piores valores de $R^{2}$, ficando a ECPI com 11 itens - seis itens dinâmicos $(1,9,13,15,17$ e 19) e cinco itens estáticos $(6$, $10,12,14,16)$. O ajustamento local e global deste modelo melhorou substancialmente, estando os índices NNFI $(0,97)$, CFI $(0,97), \operatorname{RMR}_{\text {st }}(0,03)$ e RMSEA $(0,05)$ dentro dos limites considerados satisfatórios.

Quadro 5 - Índices de ajustamento global para as AFC iniciais e finais

\begin{tabular}{|c|c|c|c|c|c|c|c|c|c|c|}
\hline \multirow{2}{*}{ Escalas } & \multicolumn{5}{|c|}{$\begin{array}{c}\text { Modelo inicial (todos os } \\
\text { itens) }\end{array}$} & \multicolumn{5}{|c|}{ Modelo final } \\
\hline & NNFI & CFI & $\mathrm{RMR}_{\mathrm{st}}$ & RMSEA & $\begin{array}{l}\mathrm{N}^{\circ} \\
\text { Itens }\end{array}$ & NNFI & CFI & $\mathrm{RMR}_{\text {st }}$ & RMSEA & $\begin{array}{l}\mathrm{N}^{\circ} \\
\text { Itens }\end{array}$ \\
\hline QCE & 0,80 & 0,80 & 0,04 & 0,05 & 42 & 0,93 & 0,94 & 0,04 & 0,04 & 20 \\
\hline ECPI & 0,84 & 0,86 & 0,07 & 0,07 & 20 & 0,97 & 0,97 & 0,03 & 0,05 & 11 \\
\hline EAEA & 0,91 & 0,92 & 0,06 & 0,06 & 22 & 0,94 & 0,95 & 0,06 & 0,05 & 20 \\
\hline SDQIII & 0,80 & 0,81 & 0,08 & 0,08 & 30 & 0,93 & 0,94 & 0,06 & 0,06 & 21 \\
\hline QADC & 0,70 & 0,71 & 0,07 & 0,05 & 48 & 0,91 & 0,92 & 0,04 & 0,04 & 24 \\
\hline
\end{tabular}

Legenda: QCE - Questionário de Competência Emocional; ECPI - Escala de Concepções Pessoais de Inteligência; EAEA - Escala de Auto-Eficácia Académica; SDQIII - Self-Description Questionnaire III; QADC - Questionário de Atribuições e Dimensões Causais. 
As dimensões causais têm sido, ao longo dos muitos anos de investigação no domínio atribucional, um construto de complexa avaliação, dificultando a construção de instrumentos de medida com boas qualidades psicométricas (Pina Neves \& Faria, 2008). Na AFC do QADC foi difícil encontrar um modelo satisfatório, uma vez que os valores iniciais para os índices de comparação eram claramente inadequados: $\mathrm{NNFI}=0,70, \mathrm{CFI}=0,71$ vs. $\mathrm{RMR}_{\mathrm{st}}=0,07$ e RMSEA $=0,05$. Após várias análises, em que fomos excluindo itens que apresentavam mau ajustamento local e introduzindo parâmetros sugeridos pelo LM Test, consistentes do ponto de vista teórico e metodológico, o modelo do QADC ficou reduzido a um total de 8 itens para cada dimensão causal: itens $6,7,9,10,11,12,13,16$. Os seus indicadores globais são médios: $\mathrm{NNFI}=0,91, \mathrm{CFI}=0,92, \mathrm{RMR}_{\mathrm{st}}=0,04$ e RMSEA $=0,04$.

Em investigações anteriores com o SDQIII, o auto-conceito Matemática foi a dimensão que apresentou melhores resultados (Faria \& Fontaine, 1992), tal como neste estudo. Assim, no primeiro modelo, os itens que contribuíram para o respectivo mau ajustamento pertencem essencialmente às dimensões do auto-conceito Português e assuntos escolares, traduzindo-se

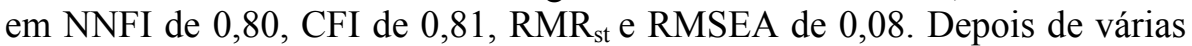
análises em que os itens com piores indicadores foram sendo excluídos (4, $10,11,14,16,19,22,28$ e 29) e em que se incluíram algumas das sugestões do LM Test, os indicadores de ajustamento local e global foram mais razoáveis: $\mathrm{NNFI}=0,93, \mathrm{CFI}=0,94, \mathrm{RMRst}=0,06$ e $\mathrm{RMSEA}=0,06$.

Na EAEA, o primeiro modelo apresentou um bom ajustamento local mas um ajustamento global menos positivo ( $\mathrm{NNFI}=0,91, \mathrm{CFI}=0,92$, $\mathrm{RMR}_{\mathrm{st}}=0,06, \mathrm{RMSEA}=0,06$ ). Já que todos os itens apresentavam bons valores de $R^{2}$ e tinham pouco erro associado, optámos por excluir os itens que em AFE's anteriores se misturaram com outras dimensões (itens 6 e 15). Assim, o segundo modelo melhorou ligeiramente os seus índices de ajustamento global, dando-se como aceite: $\mathrm{NNFI}=0,94, \mathrm{CFI}=0,95, \quad \mathrm{RMR}_{\mathrm{st}}=0,06$, RMSEA $=0,05$.

Finalmente, no que diz respeito ao QCE, os resultados corroboraram estudos nacionais e internacionais anteriores (Faria et al., 2006; Faria \& Lima Santos, 2011; Lima Santos \& Faria, 2005). Assim, a dimensão com piores resultados em termos de ajustamento local foi a capacidade para lidar com a emoção. Em termos de ajustamento global, o primeiro modelo, com todos os itens, apresentou bons índices para $\mathrm{RMR}_{\mathrm{st}}(0,04)$ e para RMSEA $(0,05)$, mas maus valores para NNFI $(0,80)$ e para CFI $(0,80)$. Excluídos os itens com piores indicadores a nível local e que contribuíram negativamente para este modelo, o QCE ficou reduzido a 20 itens: 10 itens na percepção emocional $(1,4,7,10,13,19,22,34,37,40), 8$ itens na expressão emocional $(2,8,11,17,20,26,32,38)$ e 2 itens na capacidade para lidar com a emoção $(3,12)$. Neste modelo, com 20 itens e com a introdução de uma 
covariância-erro sugerida pelo LM Test, todos os índices de ajustamento local e global são aceitáveis $-\mathrm{NNFI}=0,93, \mathrm{CFI}=0,94, \quad \mathrm{RMR}_{\mathrm{st}}=0,04 \mathrm{e}$ RMSEA=0,04 (Hu \& Bentler, 1999).

Assim, após a selecção dos itens com melhor ajustamento local e que mais contribuíram para um bom ajustamento global, procedemos à realização de uma AFC que integrou os referidos itens. Contudo, este modelo continuava a ser demasiado complexo, pelo que tivemos que ponderar reduzi-lo. Neste sentido, uma vez que o QADC foi a escala que apresentou piores resultados a nível de ajustamento local e global e que foi, também, a escala que menos se correlacionou com as outras, que revelou pior consistência e pior validade interna das respectivas dimensões e itens, optou-se pela sua exclusão da AFC para o instrumento compósito.

Então, esta análise contou com a integração de 72 itens distribuídos pelos respectivos 11 factores: percepção e expressão emocional, capacidade para lidar com a emoção; CPI dinâmica e estática; auto-eficácia Português, Matemática e escolar geral; auto-conceito Português, Matemática e assuntos escolares. No primeiro modelo os valores de partida não eram bons, pelo que pedimos uma segunda análise - Modelo 1 (Quadro 6) -, com os valores de partida dados automaticamente pelo EQS (retest).

Quadro 6 - Índices de ajustamento global dos modelos analisados

\begin{tabular}{ccccccccc}
\hline Modelos & $\chi^{2}$ & $g l$ & $\Delta \chi^{2}$ & $\Delta g l$ & NNFI & CFI & RMR $_{\text {st }}$ & RMSEA \\
\hline M1 & 6362,2 & 2429 & --- & --- & 0,91 & 0,91 & 0,05 & 0,04 \\
M2 & 6363,2 & 2432 & $-1,0$ & -3 & 0,91 & 0,91 & 0,05 & 0,04 \\
M3 & 6006,9 & 2429 & 356,3 & 3 & 0,92 & 0,92 & 0,05 & 0,04 \\
\hline
\end{tabular}

Neste modelo, assim como nos subsequentes, o valor do $\chi^{2}$ é substancialmente menor que o valor do $\chi^{2}$ de independência, rejeitando-se o modelo nulo. Os valores residuais estandardizados são menores que 2,58 e a análise da distribuição de frequência revela que a maior parte dos resíduos $(96,23 \%)$ se concentra entre os valores - 0,1 e 0,1 (portanto, próximos de zero), verificando-se que apesar de poder existir uma discrepância mínima entre o ajustamento do modelo proposto e o do modelo obtido, estes valores indicam um bom ajustamento (Byrne, 2006). Por sua vez, os índices de ajustamento global são razoáveis, já que: $\mathrm{NNFI}=0,91, \quad \mathrm{CFI}=0,91, \quad \mathrm{RMR}_{\mathrm{st}}=0,05 \quad \mathrm{e}$ RMSEA $=0,04$. Ao nível do ajustamento local, todos os itens apresentam bons, e significativos, valores de saturação, com reduzida quantidade de erro associada, sendo que os factores correspondentes ao QCE são os que apresentam itens com piores indicadores. Todos os itens capturam mais de $30 \%$ da variância dos resultados $\left(R^{2}>0,30\right)$. Apesar de globalmente os factores 
apresentarem fortes valores correlacionais entre si, correlações que envolvam os dois factores das CPI (dinâmico e estático), o auto-conceito Matemática e assuntos escolares, e as três dimensões da competência emocional tendem a revelar valores mais baixos. Estes resultados vão de encontro aos observados nas covariâncias entre factores, uma vez que parte das covariâncias que envolvem estes factores não são significativas.

Ora, a não significância das covariâncias entre alguns factores pode indicar dificuldade na estimação dos parâmetros do modelo, dada a sua complexidade e o extenso número de parâmetros considerados. Assim, para os factores cuja covariância não foi significativa, substituímos os valores de partida, que tinham sido gerados automaticamente pelo EQS, pelos respectivos valores de correlação, já que são mais exactos. Neste processo, nos pares de factores cujas correlações foram muito baixas, optámos por fixar os seus valores de partida em zero (os parâmetros não são estimados) e assumir a inexistência de correlação. São eles: CPI dinâmica - auto-conceito assuntos escolares; expressão emocional - auto-conceito Matemática; e CPI dinâmica - auto-eficácia Matemática. Esta nova AFC deu origem ao Modelo 2 (Quadro 6).

No Modelo 2 os valores residuais estandardizados, os índices de ajustamento global e local, e os valores de $R^{2}$ são muito semelhantes aos encontrados para o Modelo 1, não havendo alterações assinaláveis. As diferenças surgem para a significância das covariâncias entre os factores, já que três delas passaram a ser significativas: CPI dinâmica - auto-eficácia escolar geral; CPI estática - auto-eficácia Matemática; capacidade para lidar com a emoção - auto-eficácia Matemática. Assim, são cinco os pares de factores que continuaram sem se relacionarem significativamente: capacidade para lidar com a emoção - auto-conceito assuntos escolares; CPI dinâmica - auto-conceito Matemática; percepção emocional - auto-conceito Matemática; capacidade para lidar com a emoção - auto-conceito Matemática; CPI dinâmica - auto-conceito verbal. Estes resultados sugerem que, apesar de estas dimensões serem parte integrante da competência percebida, a competência emocional e a CPI dinâmica poderão não estar directamente associadas com o auto-conceito académico, principalmente com o auto-conceito Matemática. Relembramos que já nas análises correlacionais encontrámos valores baixos ou não significativos entre estas dimensões.

Ainda no Modelo 2, foram analisados possíveis parâmetros desajustados, através do LM Test, que deram origem à reespecificação deste modelo. Assim, foram introduzidas três covariâncias-erro (integradas uma a uma), que diminuiriam o valor do $\chi^{2}$ e que, por outro lado, faziam sentido conceptualmente: e71, e68 - itens 38 e 32 da expressão emocional (conhecer o próprio estado emocional/sentimentos); e21, e20 - itens 30 e 27 do auto-conceito Matemática (ser bom/boa a Matemática); e17, e13 - itens 24 e 18 do auto-conceito Matemática (dificuldades na Matemática). 
Quadro 7 - Valores de saturação, de erro e de $R^{2}$ para cada item do Modelo 3

\begin{tabular}{|c|c|c|c|c|c|c|c|c|c|}
\hline Dimensões & $\begin{array}{l}\mathrm{N}^{\mathrm{o}} \\
\text { item }\end{array}$ & Saturação & Erro & $R^{2}$ & Dimensões & $\begin{array}{l}\mathrm{N}^{\mathrm{o}} \\
\text { item }\end{array}$ & Saturação & Erro & $R^{2}$ \\
\hline \multirow{5}{*}{$\begin{array}{l}\text { CPI estáti- } \\
\text { ca }\end{array}$} & 6 & 0,73 & 0,68 & 0,54 & \multirow{6}{*}{$\begin{array}{c}\text { Auto- } \\
\text {-eficácia } \\
\text { Português }\end{array}$} & 1 & 0,84 & 0,55 & 0,70 \\
\hline & 10 & 0,79 & 0,61 & 0,63 & & 4 & 0,68 & 0,73 & 0,46 \\
\hline & 12 & 0,78 & 0,63 & 0,60 & & 7 & 0,66 & 0,75 & 0,44 \\
\hline & 14 & 0,85 & 0,53 & 0,72 & & 9 & 0,65 & 0,76 & 0,43 \\
\hline & 16 & 0,82 & 0,56 & 0,67 & & 12 & 0,78 & 0,63 & 0,61 \\
\hline \multirow{6}{*}{$\begin{array}{l}\text { CPI dinâ- } \\
\text { mica }\end{array}$} & 1 & 0,72 & 0,69 & 0,52 & & 18 & 0,87 & 0,50 & 0,75 \\
\hline & 9 & 0,78 & 0,62 & 0,61 & \multirow{8}{*}{$\begin{array}{c}\text { Auto- } \\
\text {-eficácia } \\
\text { Matemática }\end{array}$} & 2 & 0,81 & 0,58 & 0,66 \\
\hline & 13 & 0,61 & 0,79 & 0,38 & & 5 & 0,85 & 0,53 & 0,72 \\
\hline & 15 & 0,78 & 0,62 & 0,62 & & 8 & 0,62 & 0,79 & 0,38 \\
\hline & 17 & 0,74 & 0,67 & 0,55 & & 10 & 0,93 & 0,37 & 0,86 \\
\hline & 19 & 0,85 & 0,53 & 0,72 & & 13 & 0,94 & 0,34 & 0,89 \\
\hline \multirow{7}{*}{$\begin{array}{l}\text { Auto- } \\
\text {-conceito } \\
\text { verbal }\end{array}$} & 2 & 0,73 & 0,68 & 0,53 & & 16 & 0,89 & 0,45 & 0,80 \\
\hline & 5 & 0,62 & 0,78 & 0,39 & & 19 & 0,84 & 0,55 & 0,70 \\
\hline & 8 & 0,70 & 0,71 & 0,50 & & 21 & 0,69 & 0,72 & 0,48 \\
\hline & 17 & 0,71 & 0,70 & 0,51 & \multirow{6}{*}{$\begin{array}{l}\text { Auto- } \\
\text {-eficácia } \\
\text { escolar } \\
\text { geral }\end{array}$} & 3 & 0,82 & 0,54 & 0,67 \\
\hline & 20 & 0,72 & 0,69 & 0,52 & & 11 & 0,71 & 0,70 & 0,51 \\
\hline & 23 & 0,75 & 0,66 & 0,57 & & 14 & 0,84 & 0,55 & 0,70 \\
\hline & 26 & 0,65 & 0,76 & 0,42 & & 17 & 0,88 & 0,48 & 0,77 \\
\hline \multirow{10}{*}{$\begin{array}{c}\text { Auto- } \\
\text {-conceito } \\
\text { Matemática }\end{array}$} & 3 & 0,77 & 0,64 & 0,59 & & 20 & 0,81 & 0,59 & 0,66 \\
\hline & 6 & 0,68 & 0,74 & 0,46 & & 22 & 0,86 & 0,52 & 0,73 \\
\hline & 9 & 0,63 & 0,78 & 0,40 & \multirow{10}{*}{$\begin{array}{l}\text { Percepção } \\
\text { emocional }\end{array}$} & 1 & 0,55 & 0,83 & 0,31 \\
\hline & 12 & 0,74 & 0,68 & 0,54 & & 4 & 0,62 & 0,79 & 0,38 \\
\hline & 15 & 0,90 & 0,44 & 0,80 & & 7 & 0,63 & 0,77 & 0,40 \\
\hline & 18 & 0,77 & 0,64 & 0,59 & & 10 & 0,60 & 0,80 & 0,36 \\
\hline & 21 & 0,73 & 0,69 & 0,53 & & 13 & 0,66 & 0,75 & 0,43 \\
\hline & 24 & 0,72 & 0,69 & 0,52 & & 19 & 0,57 & 0,82 & 0,33 \\
\hline & 27 & 0,81 & 0,52 & 0,66 & & 22 & 0,65 & 0,76 & 0,42 \\
\hline & 30 & 0,72 & 0,69 & 0,52 & & 34 & 0,59 & 0,81 & 0,35 \\
\hline \multirow{12}{*}{$\begin{array}{c}\text { Auto- } \\
\text {-conceito } \\
\text { assuntos } \\
\text { escolares }\end{array}$} & 1 & 0,86 & 0,52 & 0,74 & & 37 & 0,65 & 0,76 & 0,42 \\
\hline & 7 & 0,72 & 0,70 & 0,52 & & 40 & 0,70 & 0,71 & 0,49 \\
\hline & 13 & 0,87 & 0,50 & 0,75 & \multirow{8}{*}{$\begin{array}{l}\text { Expressão } \\
\text { emocional }\end{array}$} & 2 & 0,64 & 0,77 & 0,40 \\
\hline & 25 & 0,69 & 0,73 & 0,47 & & 8 & 0,77 & 0,64 & 0,59 \\
\hline & & & & & & 11 & 0,77 & 0,64 & 0,60 \\
\hline & & & & & & 17 & 0,74 & 0,67 & 0,55 \\
\hline & & & & & & 20 & 0,65 & 0,76 & 0,42 \\
\hline & & & & & & 26 & 0,78 & 0,63 & 0,60 \\
\hline & & & & & & 32 & 0,56 & 0,83 & 0,31 \\
\hline & & & & & & 38 & 0,62 & 0,79 & 0,38 \\
\hline & & & & & Capacidade & 3 & 0,64 & 0,77 & 0,41 \\
\hline & & & & & $\begin{array}{c}\text { lidar emo- } \\
\text { ção }\end{array}$ & 12 & 0,71 & 0,70 & 0,50 \\
\hline
\end{tabular}


Surgiu, assim, o Modelo 3 (Quadro 6), com um $\chi^{2}$ significativamente mais baixo $\left(\Delta \chi^{2}=356,3 ; p<0,000\right)$ e com valores do NNFI e CFI ligeiramente mais elevados $(0,92)$, mantendo-se constantes os outros indicadores do ajustamento global. Os valores residuais são semelhantes aos dos modelos anteriores $(96,31 \%$ dos resíduos estão entre o intervalo $-0,1$ e 0,1$)$, os valores de saturação são superiores a 0,55 , a quantidade de erro associada aos itens varia entre 0,34 e 0,83 , os valores de $R^{2}$ superam 0,30 e as correlações entre os factores são as mesmas do Modelo 2 (Quadro 7).

Considerando os resultados da análise das qualidades psicométricas do QCCP, verificou-se que é possível aceitar a existência e promover a utilização de um instrumento compósito da competência percebida, que permita avaliar várias dimensões deste construto. Contudo, trata-se de um instrumento ainda em (re)construção, necessitando de mais estudos que permitam o seu refinamento e melhoramento.

\section{Discussão}

Neste trabalho, após uma discussão acerca da necessidade de construir um quadro conceptual que reúna num só construto as concepções pessoais de competência, apresentaram-se os primeiros estudos e respectivos resultados das qualidades psicométricas do Questionário Compósito de Competência Percebida, explorando-se a sua consistência interna, sensibilidade e validade de construto.

Globalmente, a AFE com os 12 factores revelou índices globais de saturação e de comunalidade satisfatórios, extraindo $44 \%$ da variância total dos resultados. Os resultados obtidos tendem a corroborar as outras análises psicométricas realizadas, pelo que procuraremos discutir aqui a sua relação. Efectivamente, as dimensões da auto-eficácia e do auto-conceito académicos tendem a misturar-se, na AFE, em factores comuns associados a Português e a Matemática, indo de encontro aos resultados correlacionais, cujos coeficientes são tanto mais elevados quanto mais "academicamente" afins forem as suas dimensões (auto-eficácia Português/auto-conceito verbal; auto-eficácia Matemática/auto-conceito Matemática). Contudo, o mesmo já não se verifica para as dimensões académicas gerais (auto-eficácia escolar geral e auto-conceito assuntos escolares), já que: os itens da auto-eficácia escolar geral misturam-se com os da auto-eficácia Matemática, verificando-se também uma forte correlação entre estas dimensões; e que parte dos itens do auto-conceito assuntos escolares saturam o Factor 1 e o Factor 2, juntamente com os itens de Matemática e verbais, respectivamente. Tal poderá sugerir que os domínios de Português e de Matemática assumem um papel de relevo, uma vez que os itens relativos aos domínios académicos gerais (auto-eficácia escolar geral e auto-conceito assuntos escolares) apresentam corre- 
lações elevadas e misturam-se com os itens de Português e de Matemática. Contudo, estes resultados podem também evidenciar fraca validade discriminativa dos domínios académicos gerais de ambos os construtos. Efectivamente, Pina Neves e Faria (2006) debateram-se com a mesma questão, pois encontraram resultados semelhantes para as dimensões da auto-eficácia: fortes associações entre a dimensão académica geral e as duas dimensões específicas (Português e Matemática). Assim, estes resultados, apoiados por estudos anteriores, parecem pôr em questão a necessidade de uma dimensão académica geral, vaga e pouco discriminativa, e/ou a existência de um factor de segunda ordem (Pina Neves \& Faria, 2006), o qual postula que os factores de primeira ordem estimados são na realidade subdimensões de um construto mais amplo. Contudo, esta hipótese poria em causa o pressuposto específico e microanalítico da auto-eficácia, exigindo uma revisão teórica, metodológica e empírica deste construto.

Apesar de grande parte dos estudos com a ECPI encontrarem dois factores distintos (estático e dinâmico - Faria, 2006) e de as AFC neste trabalho também terem revelado essa possibilidade, há que ter em consideração que: todos os itens são cotados no mesmo sentido (dinâmico), e que as duas dimensões avaliam o mesmo construto - a natureza e (im)possibilidade de desenvolvimento da inteligência. Logo, poderá ser compreensível a mistura de cinco itens estáticos no factor da CPI dinâmica da AFE (Factor 3). Efectivamente, as CPI podem ser mais dinâmicas ou mais estáticas, tratando-se de dimensões fortemente correlacionadas, e permitindo um somatório total dos itens, ou seja, o cálculo de uma dimensão total. Assim, pode colocar-se a hipótese de estarmos perante um construto passível de ser avaliado de forma bifactorial (CPI dinâmica e CPI estática), mas também como um construto unidimensional, logo, unifactorial. Contudo, mais estudos teriam de ser realizados, nomeadamente através da comparação dos resultados de uma AFC para um modelo unifactorial e para um modelo bifactorial, para pistas mais seguras e empiricamente fundamentadas serem discutidas.

Já as dimensões do QCE parecem apresentar forte validade divergente. De facto, todas as dimensões do QCE saturam factores isolados na AFE, com excepção de quatro itens da capacidade para lidar com a emoção. Apesar de esta dimensão ser menos diferenciada e consistente, o que também foi observado noutros estudos nacionais e internacionais (Faria et al., 2006; Faria \& Lima Santos, 2011; Lima Santos \& Faria, 2005), o QCE parece revelar neste estudo uma estrutura mais diferenciada e clara do que em investigações anteriores, podendo para tal ter contribuído a adaptação dos itens, preliminar e decorrente do estudo-piloto, que apresentavam piores qualidades. Assim, apesar das fortes correlações observadas entre as três dimensões da competência emocional, estas parecem possuir adequada validade divergente. 
O mesmo parece acontecer com as dimensões causais, cuja estrutura factorial é mais diferenciada do que aquela que foi encontrada por Pina Neves e Faria (2008). Efectivamente, as autoras verificaram elevada convergência entre o locus e a controlabilidade, convergência esta presente noutras investigações e profusamente discutida na literatura (Weiner, 1985). No presente estudo, o locus e a controlabilidade estão fortemente correlacionados e observa-se esta convergência entre cinco itens do locus e seis itens da controlabilidade, que saturam um único factor. Contudo, se tomarmos em consideração que se tratam de itens com as mesmas causas atribucionais e que todos os outros itens saturam factores diferenciados, o cômputo geral parece ser mais positivo. Assim, globalmente, as três dimensões causais tendem a diferenciar-se, sendo a estabilidade a dimensão mais consistente (Pina Neves \& Faria, 2008).

Contudo, a diferenciação verificada nas dimensões do QADC parece ocorrer também a nível inter-construto. De facto, apesar de as dimensões causais serem relevantes para a competência percebida dos alunos, tendo grande impacto na motivação (Perry, Stupnisky, Hall, Chipperfield, \& Weiner, 2010; Pina Neves \& Faria, 2008; Stocker, Pina Neves \& Faria, 2010; Weiner, 1985), a sua relação com as outras dimensões da competência percebida parece ser diminuta, possivelmente também devido à especificidade dos seus itens e escala de resposta, que diferem dos restantes. Este aspecto, aliado ao facto de o QADC ter apresentado os piores índices de ajustamento global e local na AFC, levou-nos, na impossibilidade de integrar todas as dimensões na AFC, pela sua complexidade, a excluir os seus itens desta análise estatística. Assim, a AFC foi realizada com as dimensões da competência percebida integradas no QCCP, com excepção do locus, da estabilidade e da controlabilidade. Esta análise permitiu aprofundar o estudo da validade de construto deste instrumento, assim como analisar a adequabilidade do seu racional teórico.

Efectivamente, nas AFC's realizadas foi possível verificar a necessidade de alteração de algumas escalas, já que em todas elas foi necessário retirar itens das análises, de modo a promover o ajustamento do respectivo modelo. Tal poderá implicar, em futuros estudos, alterações ao nível teórico e conceptual, ao nível do conteúdo/formulação dos itens e/ou a exclusão de itens que contribuem menos para a avaliação de determinada dimensão. Mais especificamente, o QCE e o QADC demonstraram ser os instrumentos que necessitam de maior atenção, ficando reduzidos na $\mathrm{AFC}$ a $50 \%$ dos seus itens. Já a EAEA e o SDQIII foram os questionários que melhores qualidades psicométricas revelaram em todas as análises, retendo na AFC 91\% e $70 \%$ dos itens, respectivamente.

O modelo final, com 11 factores, revela um ajustamento global satisfatório, com indicadores psicométricos aceitáveis. A nível do ajustamento 
local, apesar de os valores de saturação, de $R^{2}$, dos resíduos e da quantidade de erro serem adequados, existem factores cujas covariâncias não são significativas, sugerindo a sua não relação. Estes pares de factores, não significativos, concentram-se em torno das dimensões das CPI, do auto-conceito e da competência emocional. Assim, embora outros estudos evidenciem a importância destas dimensões na relação e/ou previsão do rendimento académico (Dweck, 2008; Pajares \& Schunk, 2001; Pekrun, Maier, \& Elliot, 2009; Stocker, Pina Neves, \& Faria, 2010), no presente trabalho estas parecem não se associar entre si.

Contudo, convém relembrar que foram analisadas dimensões psicológicas específicas, ou seja, dimensões que integram construtos mais alargados (i.e.: auto-conceito Matemática vs. auto-conceito académico). Assim, parece-nos possível, e explicável do ponto de vista teórico, que dimensões mais gerais (como CPI total, competência emocional e auto-conceito académico) possam apresentar relações significativas entre si, mas que dimensões mais específicas, por se diferenciarem mais, não se relacionarem significativamente entre si. Mesmo assim, são resultados que merecem especial atenção em futuros estudos que integrem estas dimensões psicológicas, de modo a explorar melhor a sua relação.

\section{Conclusões}

Perante estes resultados, parece-nos fundamental a prossecução de estudos que aprofundem as potencialidades e os limites do QCCP, já que globalmente se revelou um instrumento útil no que diz respeito à avaliação da competência percebida. Tendo apresentado bons níveis de consistência interna e de sensibilidade, mas uma validade discriminativa e de construto menos claras, seria importante replicar estas análises com diferentes amostras e/ou com várias amostras em simultâneo (i.e.: amostra de validação e de calibração ou recorrendo ao método bootstrapping), verificando a estabilidade dos resultados. Efectivamente, apesar de a amostra deste estudo ter sido seleccionada aleatoriamente e representar diferentes realidades da cidade do Porto (áreas geográficas, escolas, anos, cursos...) seria útil replicá-lo com alunos de outras zonas do país, nomeadamente mais rurais, e procurar maior representatividade do NSE.

Seria também importante realizar estudos de invariância métrica, com o objectivo de avaliar a estabilidade da estrutura do QCCP em diferentes grupos (género, nível sócio-económico, ano de escolaridade, curso...). Além disso, testar novos modelos através da AFC, nomeadamente com as dimensões alargadas dos construtos (CPI, dimensões causais, auto-conceito e auto-eficácia académicos, competência emocional), e comparando modelos alter- 
nativos nos casos das CPI (uni e bifactorial), do auto-conceito e da auto-eficácia (com e sem dimensões académicas gerais), poderá contribuir para a ponderação da adequabilidade dos itens e das dimensões do QCCP, podendo levar à reformulação e/ou eliminação de itens/dimensões, no sentido de melhorar e refinar este instrumento compósito de competência percebida.

No que diz respeito à intervenção escolar e à prática educacional, este estudo pode ser um primeiro passo para, no futuro, existir um instrumento compósito de competência percebida, mais curto e de fácil preenchimento e cotação, que permita aos profissionais escolares aceder às várias dimensões do perfil motivacional do aluno e, assim, adequar e implementar eficazmente estratégias, de acordo com as respectivas características motivacionais, que promovam a motivação para a aprendizagem e a prossecução da mestria.

Assim, partilhamos da opinião que a construção e a validação de um instrumento é sempre um processo inacabado e dinâmico, considerando este trabalho como um passo preliminar na construção e validação de um instrumento compósito de competência percebida com boas potencialidades de utilização no contexto escolar.

\section{Referências}

Bandura, A. (1977). Self-efficacy: Toward a unifying theory of behavioral change. Psychologigal Review, 84, 191-215.

Byrne, B. M. (2006). Structural equation modeling with EQS: Basic concepts, applications, and programming ( $2^{\mathrm{a}}$ ed.). New York, NY: Psychology Press.

Ciochină, L., \& Faria, L. (2006). Concepções pessoais de inteligência de estudantes portugueses e romenos: Estudo preliminar de análise factorial confirmatória. Psychologica, 41, 171-191.

Dweck, C. S. (1996). Implicit theories as organizers of goals and behavior. In P. Gollwitzer \& J. Bargh (Eds.), The psychology of action: Linking cognition and motivation to behavior (pp. 69-90). New York, NY: The Guildford Press.

Dweck, C. S. (1999). Self-theories: Their role in motivation, personality and development. Philadelphia: Psychology Press.

Dweck, C. S. (2008). Brainology transforming students' motivation to learn. Independent School, 67, 110-119.

Faria, L. (2006). Escala de Concepções Pessoais de Inteligência (E.C.P.I.). In M. M. Gonçalves, M. R. Simões, L. S. Almeida \& C. Machado (Coords.), Avaliação Psicológica - Instrumentos validados para a população portuguesa ( $2^{\mathrm{a}}$ ed. revista, Vol. 1, pp. 121-133). Coimbra: Quarteto Editora.

Faria, L. (2008). Motivação para a competência: O papel das concepções pessoais de inteligência no desempenho e no sucesso. Porto: Livpsic/Legis Editora.

Faria, L., \& Fontaine, A. M. (1992). Estudo de adaptação do Self-Description Questionnaire III (SDQ III) a estudantes universitários portugueses. Psychologica, $8,41-49$. 
Faria, L., \& Lima Santos, N. (2011). Questionário de Competência Emocional (QCE). In C. Machado, M. M. Gonçalves, L. S. Almeida \& M. R. Simões (Eds.), Instrumentos e contextos de avaliação psicológica (Vol. 1, pp. 67-80). Coimbra: Edições Almedina, SA.

Faria, L., Lima Santos, N., Takšic, V., Räty, H., Molander, B., Holmström, S., Jansson, J., Avsec, A., Extremera, N., Fernández-Barrocal, P., \& Toyota, H. (2006). Cross-cultural validation of the Emotional Skills and Competence Questionnaire (ESCQ). Psicologia, 20, 95-127.

Faria, L., Pina Neves, S., Stocker, J., Fontes Costa, A., \& Costa, M. (2010). Concepções pessoais de competência de alunos e eficácia colectiva de escolas: Que contributos para o sucesso no ensino secundário? Porto: Livpsic/Legis Editora.

Fredrickson, B. L. (2001). The role of positive emotions in positive psychology: The broaden-and-build theory of positive emotions. American Psychologist, 56, 218-226.

Harter, S. (1992). The relationship between perceived competence, affect, and motivational orientation within the classroom: Processes and patterns of change. In A. K. Boggiano \& T. S. Pittman (Eds.), Achievement and motivation: A social-development perspective (pp. 77-114). New York, NY: Cambridge University Press.

Hattie, J. (1992). Self-concept. Hillsdale: Lawrence Erlbaum Associates.

Hu, L., \& Bentler, P. M. (1999). Cutoff criteria for Fit Indexes in covariance structure analysis: Conventional criteria versus new alternatives. Structural Equation Modeling, 6, 1-55.

Lima Santos, N., \& Faria, L. (2005). Inteligência emocional: Adaptação do Emotional Skills and Competence Questionnaire (ESCQ) ao contexto Português. Revista da Faculdade de Ciências Humanas e Sociais da UFP, 2, 275-289.

Maroco, J. (2010). Análise de Equações Estruturais: Fundamentos teóricos, Software \& Aplicações. Lisboa: Report Number.

Marsh, H. W., Byrne, B., \& Shavelson, R. J. (1988). A multifaceted academic self-concept: Its hierarchical structure and its relation to academic achievement. Journal of Educational Psychology, 80, 366-380.

Marsh, H. W., \& Shavelson, R. J. (1985). Self-concept: Its multifaceted, hierarchical structure. Educational Psychologist, 20, 107-125.

Mayer, J. D., \& Salovey, P. (1997). What is emotional intelligence? In P. Salovey \& D. Sluyter (Eds.), Emotional development and emotional intelligence: Educational implications (pp. 3-31). New York, NY: Basic Books.

Pajares, F., \& Schunk, D. H. (2001). Self-beliefs and school success: Self-efficacy, self-concept, and school achievement. In R. Riding \& S. Rayner (Eds.), Perception (pp. 239-266). London: Ablex Publishing.

Pekrun, R., Maier, M. A., \& Elliot, A. J. (2009). Achievement goals and achievement emotions: Testing a model of their joint relations with academic performance. Journal of Educational Psychology, 101, 115-135.

Perry, R. P., Stupnisky, R. H., Hall, N. C., Chipperfield, J. G., \& Weiner, B. (2010). Bad starts and better finishes: Attributional retraining and initial performance 
in competitive achievement settings. Journal of Social and Clinical Psychology, 29, 668-700.

Pietsch, J., Walker, R., \& Chapman, E. (2003). Self-concept, self-efficacy, and performance in mathematics during secondary school. Journal of Educational Psychology, 95, 589-603.

Pina Neves, S., \& Faria, L. (2005). Concepções pessoais de competência: Da integração conceptual à intervenção psicopedagógica. Psicologia,18, 101-128.

Pina Neves, S., \& Faria, L. (2006). Construção, adaptação e validação da Escala de Auto-Eficácia Académica (EAEA). Psicologia, 20, 45-68.

Pina Neves, S., \& Faria, L. (2007). Auto-eficácia académica e atribuições causais em Português e Matemática. Análise Psicológica, 25, 635-652.

Pina Neves, S., \& Faria, L. (2008). Atribuições e dimensões causais: Reformulação, adaptação e validação de um questionário. Psychologica, 48, 47-75.

Salovey, P., Mayer, J. D., \& Goldman, S. L. (1995). Emotional attention, clarity, and repair: Exploring emotional intelligence using the Trait Meta-Mood Scale. In J. W. Pennebaker (Ed.), Emotion, disclosure and health (pp. 125-154). Washington, DC: American Psychological Association.

Satorra, A., \& Bentler, P. M. (1994). Corrections to test statistics and standard errors in covariance structure analysis. In A. von Eye \& C.C. Clogg (Eds.), Latent variables analysis: Applications for developmental research (pp. 399-419). Thousand Oaks, CA: Sage.

Shavelson, R. J., Hubner, J. J., \& Stanton, G. C. (1976). Validation of construct interpretations. Review of Educational Research, 46, 407-441.

Stocker, J., Pina Neves, S., \& Faria, L. (2010). Competência percebida e realização escolar: Que relações em alunos do ensino secundário? Psychologica, 52, 427$-446$.

Weiner, B. (1985). An attributional theory of achievement motivation and emotion. Psychological Review, 92, 548-543.

Weiner, B. (2008). Reflections on the history of attribution theory and research: People, personalities, publications, problems. Social Psychology, 39, 151-156. 